\title{
Cell-penetrating cationic siRNA and lipophilic derivatives efficient at nanomolar concentrations in the presence of serum and albumin
}

\author{
Phanélie Perche, Marc Nothisen, Jérémy Bagilet, Jean-Paul Behr, Mitsuharu Kotera, Jean-Serge Remy * \\ Laboratoire de Chimie Génétique, C.A.M.B. UMR 7199, Université de Strasbourg and C.N.R.S., Laboratory of Excellence MEDALIS, Faculté de Pharmacie, F-67401 Illkirch, France
}

\section{A R T I C L E I N F O}

Article history:

Received 10 January 2013

Accepted 17 April 2013

Available online 29 April 2013

\section{Keywords:}

ZNA

Cationic oligonucleotides

Chemically modified siRNA

Lipophilic siRNA

Cholesteryl-siRNA

RNA interference

\begin{abstract}
A B S T R A C T
Despite its considerable interest in human therapy, in vivo siRNA delivery is still suffering from hurdles of vectorization. We have shown recently efficient gene silencing by non-vectorized cationic siRNA. Here, we describe the synthesis and in vitro evaluation of new amphiphilic cationic siRNA. $\mathrm{C}_{12^{-}},\left(\mathrm{C}_{12}\right)_{2^{-}}$and cholesteryl-spermine ${ }_{x}$-siRNA were capable of luciferase knockdown at nanomolar concentrations without vectorization (i.e. one to two orders of magnitude more potent than commercially available cholesteryl siRNA). Moreover, incubation in the presence of serum did not impair their efficiency. Finally, amphiphilic cationic siRNA was pre-loaded on albumin. In A549Luc cells in the presence of serum, these siRNA conjugates were highly effective and had low toxicity.
\end{abstract}

(C) 2013 Published by Elsevier B.V.

\section{Introduction}

Since its discovery in 1998 [1], RNA interference has gained tremendous interest because of its ability to knockdown gene expression. Identification of siRNA as key intermediates in such phenomena in mammals [2] has allowed RNA interference based therapies to reach clinical trials rapidly [3]. But the two major limitations to in vitro and in vivo use of siRNA are their lack of chemical and enzymatic stability and their inability to enter cells. A wide variety of carriers has thus been developed to preserve their integrity and transport them into cells. Among them, synthetic particle-forming vectors: cationic lipids, polymers, dendrimers or peptides that interact with both anionic nucleic acids and cell membranes have displayed excellent in vitro capacities. Nevertheless, they face several in vivo limitations, due to their fairly high molecular weight, including immune response [4,5], non-specific effects, aggregation on larger anionic constructs and/or poor tissue diffusion. Normally, delivery of molecules instead of particles should solve most of these problems. This can be achieved by chemical siRNA conjugation to residues responsible for their internalization. According to such strategy, siRNA conjugation to lipidic moieties, polymers or cell-penetrating peptides [6-11] successfully knocked down gene expression. A cholesteryl derivative

\footnotetext{
Abbreviations: ACN, acetonitrile; DMT, dimethoxytrityl; EMAM, ethanolic methylamine/aqueous methylamine; MALDI-TOF, matrix assisted laser desorption/ionization - time of flight; MOPS, 3-(N-morpholino)propanesulfonic acid; ON, oligonucleotide; PAGE, polyacrylamide gel electrophoresis; RNA, ribonucleic acid; SDS, sodium dodecyl sulfate; siRNA, small interfering RNA; TEAA, triethylammonium acetate; TEM, transmission electron microscopy; THF, tetrahydrofuran; TOM, tri-isopropyl silyloxymethyl; UV, ultraviolet; ZNA, zip nucleic acids.

* Corresponding author. Tel.: + 333688541 17; fax: + 33368854306.

E-mail address: remy@unistra.fr (J.-S. Remy).
}

of siRNA is also commercially available, but it contains chemical and undisclosed modifications on the nucleic acid backbone and/or phosphodiester linkage, and is efficient only at micromolar concentration, without serum [12]. Moreover, the in vivo effect of siRNA conjugation was either limited [7] or necessitated high doses [7,9,10].

In our case, oligonucleotide conjugates were obtained by a stepwiseautomated synthesis developed in our laboratory $[13,14]$. The repetitive introduction of a natural polyamine, spermine, at the 5' end of siRNA passenger strand resulted in siRNA with an overall cationic charge [15]. Such conjugates exhibited in vitro carrier free transfection and gene silencing [15] under serum free conditions. As siRNA backbones remained chemically unmodified to prevent any loss of biological activity or selectivity, and were not protected by a carrier, we anticipated that siRNA resistance to nucleases would be decreased.

We thus synthesized three lipid-cationic siRNA analogues and hypothesized that association of the lipidic moiety of cationic siRNA to serum proteins could provide molecular carriers that would enable intravenous circulation of siRNA and sterically protect them from degradation by nucleases. As albumin accounts for $60 \%$ of human plasma proteins and has already been used as molecular carrier for lipidic siRNA [10], it was chosen for this study.

We thus report here an in vitro study to compare the efficiency of cationic and lipid-cationic siRNA conjugates, their toxicity, and their resistance to serum degradation, as well as the impact of siRNA preassociation to the albumin molecular carrier on their efficiency.

\section{Materials and methods}

All oligonucleotide synthesis reagents and purification cartridges (GlenPak RNA) were purchased from Glen Research/Eurogentec 
(Paris, France) except for external DNA synthesis grade acetonitrile, which was provided by Carlo Erba-Sds (Val de Reuil, France). DMTspermine phosphoramidite was synthesized according to published procedure [13] and precipitated in pentane. Oligonucleotides and oligonucleotide conjugates syntheses ( $1 \mu \mathrm{mol}$ scale) were performed on an automated Expedite 8900 Nucleic Acid Synthesis System (GMI Inc., USA) with Expedite software, using TOM-protected phosphoramidites, standard capping reagents (cap Mix A: $\mathrm{Ac}_{2} \mathrm{O} / \mathrm{THF}$ 1:9, Cap mix B: 10\% n-methyl imidazole/THF/Pyridine: 1:8:1), 5-Benzylthio-1H-tetrazole in acetonitrile as activator and $0.02 \mathrm{M} \mathrm{I}_{2}$ in THF/Pyridine/ $\mathrm{H}_{2} \mathrm{O}$ as oxidizing solution. Lipidic moieties were introduced with cholesterol TEG or C12 -spacer phosphoramidites (Glen Research). Coupling yields were assessed by measuring the absorbance at $504 \mathrm{~nm}$ of recovered DMT fractions diluted in $100 \mathrm{~mL}$ 3\% TCA/dichloromethane solution on a Cary 100 Bio Spectrophotometer (Varian, Les Ulis, France). Oligonucleotides were freeze-dried on a Savant Speed Vac concentrator SVC 100H (Thermo Fisher, Illkirch, France). MALDI-TOF mass spectra were obtained in the positive mode on a Bruker Daltonics (Wissembourg, France) Ultraflex apparatus using hydroxypicolinic acid or trihydroxyacetophenone combined with diammonium citrate as matrix.

\subsection{Oligonucleotide synthesis}

To obtain oligonucleotide conjugates, standard instrumental protocol for a $1 \mu \mathrm{mol}$ scale RNA synthesis was used with the following modifications: 1) increased wash volume after TCA deblocking (total volume of ca. $4 \mathrm{~mL}$ ) for complete DMT recovery, 2) extended capping cycle time (3 min), 3) extended spermine coupling cycle (4 min), 4) extended cholesteryl TEG or $C_{12}$ spacer coupling time (15 min). The GL3 siRNA sequence was designed to hybridize to nucleotides 154-172 of the modified Photinus pyralis firefly luciferase gene (sequence given in Table 1). All the oligonucleotides were synthesized with final DMT-ON conditions. Average coupling yields were $>97 \%$ for nucleotide couplings and $>95 \%$ for spermine couplings. Oligonucleotide cleavage from the support and deprotection were achieved according to manufacturer's protocol [16], with EMAM deprotection duration increased up to one night. Oligonucleotide purification was carried out on GlenPak RNA cartridges. The standard protocol underwent slight modifications: 1) before oligonucleotide loading onto the column, $1 \mathrm{~mL}$ acetonitrile followed by $1 \mathrm{~mL}$ TEAA were passed through, 2) final elution was performed by, a) a $70 \% \mathrm{NH}_{3}(1 / 20) / 30 \%$ ACN elution for CholS $\mathrm{S}_{30}$ [GL3ss] and $\left(\mathrm{C}_{12}\right)_{2} \mathrm{~S}_{30}$ [GL3ss] followed by $2.5 \mathrm{M}$ acetic acid neutralization $(50 \mu \mathrm{L})$, b) a $0.07 \mathrm{M} \mathrm{NH}_{4} \mathrm{CO}_{3} / 70 \% \mathrm{ACN}$ elution for Chol[GL3ss], c) a $0.07 \mathrm{M} \mathrm{NH}_{4} \mathrm{CO}_{3} / 70 \%$ ACN elution for other samples. Oligonucleotide-containing fractions were pooled, lyophilised

Table 1

Syntheses yields of sense strands and mass spectrometry data.

\begin{tabular}{|c|c|c|c|c|}
\hline $\begin{array}{l}\text { Name } \\
\left(5^{\prime}-3^{\prime}\right)\end{array}$ & Sequence $\left(5^{\prime}-3^{\prime}\right)$ & $\begin{array}{l}\text { Yield } \\
\text { (nmol) }\end{array}$ & $\begin{array}{l}{[\mathrm{MH}]^{+}} \\
\text {calc. (Da) }\end{array}$ & $\begin{array}{l}{[\mathrm{MH}]^{+}} \\
\text {obs. (Da) }\end{array}$ \\
\hline $\mathrm{S}_{30}[\mathrm{GL} 3 \mathrm{ss}]$ & $\begin{array}{l}\mathrm{S}_{30}-\mathrm{CUUACGCUG} \\
\text { AGUACUUCGATT }\end{array}$ & 15 & 18,863 & 18,844 \\
\hline $\mathrm{CholS}_{30}[\mathrm{GL} 3 \mathrm{ss}]$ & $\begin{array}{l}\text { Chol-S }_{30} \text {-CUUACGCU } \\
\text { GAGUACUUCGATT }\end{array}$ & 5 & 19,619 & 19,776 \\
\hline $\mathrm{C}_{12} \mathrm{~S}_{30}[\mathrm{GL} 3 \mathrm{ss}]$ & $\begin{array}{l}\mathrm{C}_{12}-\mathrm{S}_{30} \text {-CUUACGCU } \\
\text { GAGUACUUCGATT }\end{array}$ & 12 & 19,128 & 19,194 \\
\hline$\left(C_{12}\right)_{2} S_{30}[G L 3 s s]$ & $\begin{array}{l}\left(C_{12}\right)_{2}-S_{30} \text {-CUUACGC } \\
\text { UGAGUACUUCGATT }\end{array}$ & 4 & 19,392 & 19,382 \\
\hline $\mathrm{S}_{30}[$ Ctrlss $]$ & $\begin{array}{l}\mathrm{S}_{30} \text {-AUGUCUACUGG } \\
\text { CAGUCCUGTT }\end{array}$ & 16 & 18,879 & 19,046 \\
\hline CholS $_{30}[$ Ctrlss] & $\begin{array}{l}\text { Chol-S }_{30} \text {-AUGUCUAC } \\
\text { UGGCAGUCCUGTT }\end{array}$ & 4 & 19,635 & n.d. \\
\hline $\mathrm{C}_{12}[\mathrm{GL} 3 \mathrm{ss}]$ & $\begin{array}{l}\mathrm{C}_{12} \text {-CUUACGCUG } \\
\text { AGUACUUCGATT }\end{array}$ & 96 & 6872 & 6879 \\
\hline$\left(\mathrm{C}_{12}\right)_{2}[\mathrm{GL} 3 \mathrm{ss}]$ & $\begin{array}{l}\left(\mathrm{C}_{12}\right)_{2} \text {-CUUACGCU } \\
\text { GAGUACUUCGATT }\end{array}$ & 117 & 7136 & 7148 \\
\hline Chol[GL3ss] & $\begin{array}{l}\text { Chol-CUUACGCUG } \\
\text { AGUACUUCGATT }\end{array}$ & 17 & 7364 & 7372 \\
\hline
\end{tabular}

on a Speed Vac concentrator, dissolved in RNAse-free water (Qiagen, Hilden, Germany) and stored at $-20^{\circ} \mathrm{C}$. Neither precipitation nor aggregation was seen during the freeze-drying process. Naked oligonucleotides GL3as and GL3ss were purchased from Eurogentec.

Overall yields listed in Table 1 were calculated from the final stock solutions concentrations by measurement of their $260 \mathrm{~nm}$ absorption [13].

\subsection{Duplex hybridization}

Following RNA strands were annealed in RNAse-free water by heating 2 min at $94{ }^{\circ} \mathrm{C}$ followed by slow cooling: $\mathrm{S}_{30} \mathrm{GL} 3$, Chols ${ }_{30} \mathrm{GL} 3, \mathrm{C}_{12} \mathrm{~S}_{30} \mathrm{GL} 3$, $\left(\mathrm{C}_{12}\right)_{2} \mathrm{~S}_{30} \mathrm{GL} 3, \mathrm{~S}_{30} \mathrm{Ctrl}$, CholS ${ }_{30} \mathrm{Ctrl}$, CholGL3, $\mathrm{C}_{12} \mathrm{GL} 3,\left(\mathrm{C}_{12}\right)_{2} \mathrm{GL} 3$ and GL3. The Ctrl siRNA sequence was described as universal negative control designed for use in Human, Mouse or Rat cells. The final concentration of all siRNA stock solutions was $20 \mu \mathrm{M}$.

\subsection{Gel electrophoresis analysis}

RNA oligonucleotide conjugates and related duplexes hybridized as above were analysed by migration of 200 pmol single and double stranded RNA mixed with $1 / 25$ th diluted Laemmli buffer, at $120 \mathrm{~V}$ for $90 \mathrm{~min}$. The gel electrophoresis was achieved through a NuPAGE $4-12 \%$ gradient Bis-Tris denaturating gel on a XCell Sure Lock $^{\mathrm{TM}}$ Mini-Cell apparatus (Invitrogen, Carlsbad, CA, USA) with MOPS-SDS $1 \times$ as running buffer. Oligospermine-oligonucleotide conjugates and siRNA duplexes were visualized by UV shadowing.

\subsection{Transmission electron microscopy (TEM)}

Ten microliters of siRNA duplex samples were transferred onto 300 mesh formvar-coated copper grids for 1 min (Ted Pella, Redding, CA, USA). Grids with adherent samples were wicked from one side, placed for $30 \mathrm{~s}$ on a $50 \mu \mathrm{L}$ drop of $2 \%$ uranyl acetate, wicked again and air dried. Images were taken with a TEM Philips CN12 apparatus.

\subsection{Cell culture}

A549Luc cells stably expressing large amounts of luciferase GL3 $\left((1-2) \times 10^{10} \mathrm{RLU} / \mathrm{mg}\right.$ protein) were obtained by transfecting human lung carcinoma A549 cells (CCL-185; ATCC) with pGL3Luc plasmid (Clontech, Mountain View, CA, USA) using jetPEI ${ }^{\mathrm{TM}}$ as delivery system (Polyplus-Transfection, Illkirch, France). Cells were grown in RPMI 1640 medium (Eurobio, Les Ulis, France) supplemented with 10\% FBS (Perbio, Brebieres, France), $2 \mathrm{mM}$ L-glutamine, $100 \mathrm{U} / \mathrm{mL}$ penicillin, $100 \mu \mathrm{g} / \mathrm{mL}$ streptomycin (Eurobio) and maintained under $0.8 \mu \mathrm{g} / \mathrm{mL}$ G418 selection (Promega, Madison, WI, USA) at $37{ }^{\circ} \mathrm{C}$ in a $5 \% \mathrm{CO}_{2}$ humidified atmosphere.

\subsection{Transfection with oligospermine-oligonucleotide conjugates}

Twenty-four hours prior to transfection, $2.5 \times 10^{4}$ A549 Luc cells were seeded per well in 24-well tissue culture plates (Corning, NY, USA). The required amounts of cationic or lipophilic cationic siRNA duplexes were diluted up to $100 \mu \mathrm{L}$ in serum-free OPTI-MEM (Gibco, Grand Island, NY, USA) or in a filtered solution of bovine serum albumin (Sigma, St. Louis, MO, USA) at final concentration of $20 \mathrm{mg} / \mathrm{mL}$ completed with OPTI-MEM. In the latter case, samples were mixed and incubated $40 \mathrm{~min}$ at room temperature to favour association between cationic siRNA and albumin. Target or control siRNA conjugated with 30 spermines units prepared in OPTI-MEM or OPTI-MEM-albumin were then added onto the cells in the presence $(10 \%)$ or absence of serum in $0.5 \mathrm{~mL}$ RPMI 1640 medium. After $4 \mathrm{~h}$ of incubation, the final volume was completed to $1 \mathrm{~mL}$ with medium to obtain $10 \%$ serum concentration. For positive controls, cells were transfected with $10 \mathrm{nM}$ of specific GL3 siRNA and lipophilic GL3 siRNA vectorized 
with $1.3 \mu \mathrm{L}$ of Interferin ${ }^{\mathrm{TM}}$ (Polyplus-Transfection, Illkirch, France) according to the supplier recommendations. All experiments were done in triplicate.

\subsection{Quantification of the luciferase gene silencing}

Luciferase gene expression was determined $48 \mathrm{~h}$ after delivery with a Luciferase Assay System (Promega, Charbonnières, France) according to manufacturer's instructions. The luminescence was quantified from $2 \mu \mathrm{L}$ of cell lysate with a Centro LB luminometer (Berthold, Thoiry, France). Protein concentration in cell lysate was measured by using a BCA assay kit (Interchim, Montluçon, France), according to manufacturer's instructions. After expressing the luciferase activity as relative light units integrated over $10 \mathrm{~s}$ per $\mathrm{mg}$ of cell protein (RLU/ $\mathrm{mg}$ ), the luciferase gene silencing was calculated relative to the luciferase activity of non-transfected A549Luc cells.

\section{Results}

In this report, three different lipids were conjugated to cationic oligonucleotides: a cholesterol moiety and two aliphatic chains bearing 12 or 24 carbons (Fig. 1).

Following a previous study [15], we used a 19-nt long sequence with 2 dT overhangs: the GL3 sequence targeting firefly luciferase gene. Likewise, 30 spermines were coupled to afford siRNA optimum transfection and activity.

Subsequently to RNA synthesis, spermine and lipid phosphoramidites were conjugated with high yields ( $\geq 95 \%$ ) with minor changes of usual coupling cycle. After deprotection and purification on affinity chromatography cartridges with slightly improved protocols, lipophilic cationic
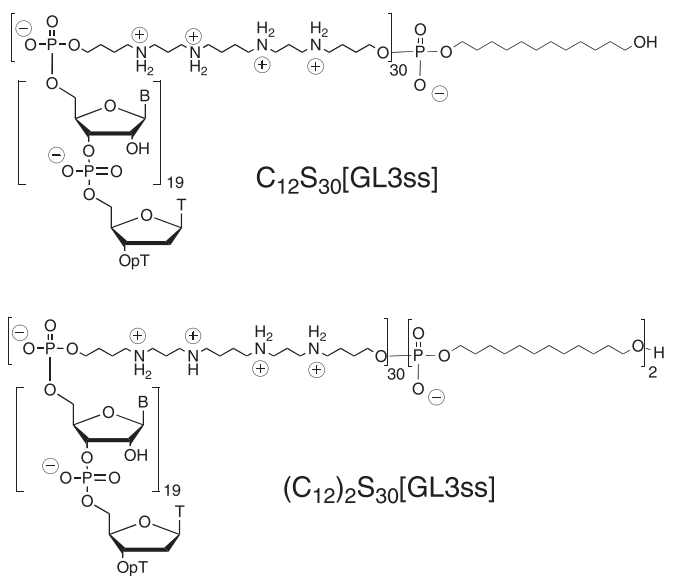

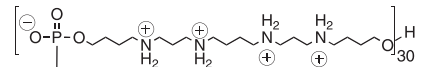

$$
\begin{aligned}
& {\left[\sum_{O-\dot{P}=0}^{O}\right]_{19}^{B}} \\
& \text { ó } \\
& { }_{0}^{0} \mathrm{~s}_{30} \text { [GL3ss] }
\end{aligned}
$$

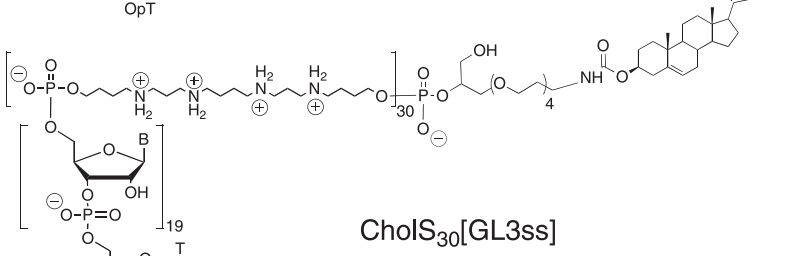

oligonucleotides conjugates and related controls were firstly characterized by mass spectroscopy (see SI), then by SDS-PAGE. Both single stranded RNA and hybridized RNAs were analysed by gel electrophoresis, in experimental conditions generally used for protein analysis (denaturating gel), with UV shadowing (Fig. 2).

Single stranded RNA without spermines appeared near or with the migration front (bottom), while spermine-containing oligonucleotides were much more retarded on the gel (top). Formation of spermine-containing duplexes was confirmed by the slight shift (higher retardation) observed between single-strand (lanes a, c, e, and g) and duplex bands (lanes b, d, f, and h). Control oligonucleotides (without spermines) were also migrating near/with the migration front (i-l). Control CholGL3 (k) was more retarded on the gel than other related controls.

TEM experiments further characterized cationic siRNA and their lipophilic counterparts. At $100 \mathrm{nM}, \mathrm{S}_{30} \mathrm{GL} 3$ exhibited mostly 4-6 nm spots (indicated by black arrows, Fig. 3a) that might correspond to individual or very few siRNA molecules, as controls did not show the same structures (data not shown).

Some of the material also appeared as particles of $20 \mathrm{~nm}$, along with few higher size granular particles of $60 \mathrm{~nm}$, showing the ability of cationic siRNA to self-assemble. Chol $\mathrm{S}_{30} \mathrm{GL} 3$ displayed structures clearly reminiscent of tubular micelles (Fig. 3b) along with few higher size particles (Fig. 3b inset). Chol $\mathrm{S}_{30} \mathrm{GL} 3$ oblong structures argue in the favour of a dynamic system [17]. Out of the four cationic siRNA, $\mathrm{C}_{12} \mathrm{~S}_{30} \mathrm{GL} 3$ showed the highest percentage of large granular particles with $15-20 \mathrm{~nm}$ and 40-50 nm populations (Fig. 3c). $\left(\mathrm{C}_{12}\right)_{2} \mathrm{~S}_{30} \mathrm{GL} 3$ showed mostly round shaped micellar structures along with $25 \mathrm{~nm}$ granular particles (Fig. 3d). All compounds were incubated for $30 \mathrm{~min}$ with $20 \mathrm{mg} / \mathrm{mL}$ (ca. one thousand molar equivalents) albumin before observation by TEM. None of the previously described structures were visible, whereas at lower albumin concentration $(0.1 \mathrm{mg} / \mathrm{mL})$ they were still present (data not shown). These observations strongly suggest the association of oligonucleotides and albumin, and therefore the disappearance of micellar structures.

Human lung cells A549Luc were used to assess RNA interference efficiency. This cell line stably and highly expresses luciferase $\left([1-2] \times 10^{10} \mathrm{RLU} / \mathrm{mg}\right.$ protein). Luciferase gene expression knockdown was observed after $48 \mathrm{~h}$ of siRNA incubation, by luminescence measurement. Optimal time-frame for luciferase knock-down measurement was found to be between 30 to $80 \mathrm{~h}$ post-transfection (data not shown). Forty-eight hours of incubation were therefore used, in accordance to what is usually found in the literature. Toxicity was evaluated by cellular protein measurement. Unless otherwise stated, all siRNA were deposited on cells without transfection agent.

Initial experiments were carried out under serum free conditions: cells were supplemented with serum $4 \mathrm{~h}$ after siRNA addition (without removal of the ON). First, the optimum concentration for siRNA activity was determined (Fig. 4). It has to be noticed that we did not consider silencing $\leq 70 \%$ to be biologically relevant (hatched line). At 100 and $50 \mathrm{nM}$, self-penetrating cationic siRNA inhibited luciferase expression at 90 and $80 \%$, respectively. RNA interference was totally abolished at $10 \mathrm{nM}$. Strong toxicity was visible at $100 \mathrm{nM}$ and detectable at $50 \mathrm{nM}$.

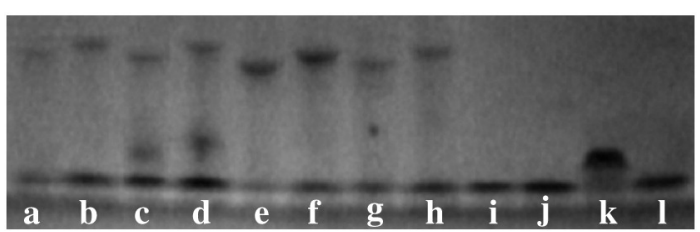

Fig. 2. PAGE analysis. Oligonucleotides inside brackets are single stranded a. $\mathrm{C}_{12} \mathrm{~S}_{30}$ [GL3ss], b. $C_{12} S_{30} G L 3$, c. CholS $S_{30}[G L 3 s s]$, d. Chol $S_{30} G L 3$, e. $S_{30}[G L 3 s s]$, f. $S_{30} G L 3$, g. $\left(C_{12}\right)_{2} S_{30}[G L 3 s s]$, h. $\left(C_{12}\right)_{2} S_{30} G L 3$, i. [GL3as], j. $C_{12}$ [GL3ss], k. Chol[GL3ss], l. $\left(C_{12}\right)_{2}$ [GL3ss].

Fig. 1. Cationic oligonucleotide and lipophilic derivatives. 


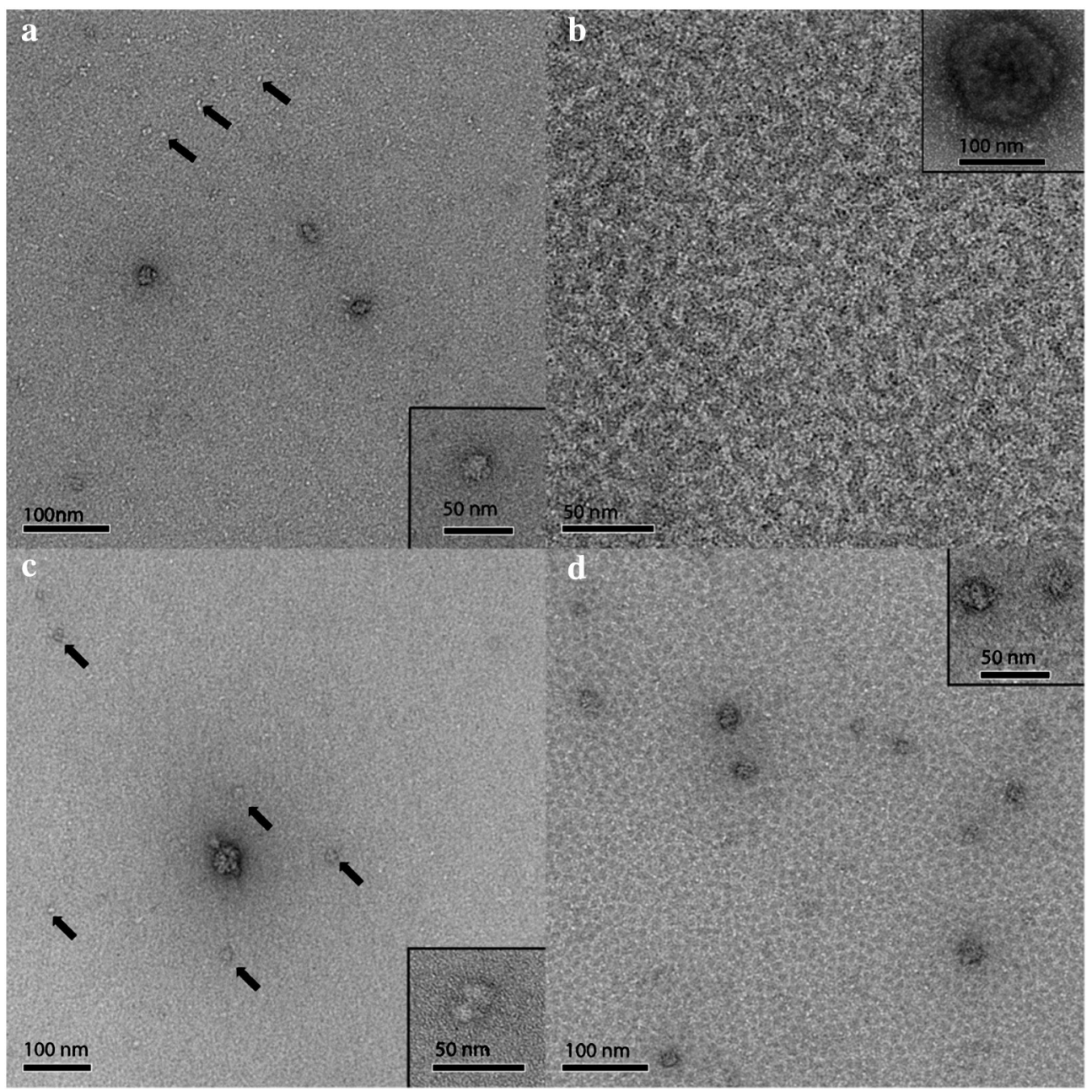

Fig. 3. Transmission electron micrographs: a. $\mathrm{S}_{30} \mathrm{GL} 3$; b. Chol $\mathrm{S}_{30} \mathrm{GL} 3$; c. $\mathrm{C}_{12} \mathrm{~S}_{30} \mathrm{GL} 3$; d. $\left(\mathrm{C}_{12}\right)_{2} \mathrm{~S}_{30} \mathrm{GL} 3$.

The cationic lipophilic derivatives were globally less efficient than $\mathrm{S}_{30} \mathrm{GL}$. At $100 \mathrm{nM}$, only $82 \%$ (CholS ${ }_{30} \mathrm{GL} 3$ ) down to $70 \%\left(\mathrm{C}_{12} \mathrm{~S}_{30} \mathrm{GL} 3\right.$ and $\left.\left(\mathrm{C}_{12}\right)_{2} \mathrm{~S}_{30} \mathrm{GL} 3\right)$ gene silencing was obtained. Moreover, neglectable silencing was obtained at $50 \mathrm{nM}$. However, cell viability was strongly increased for all lipophilic conjugates ( $\geq 90 \%$ of cell proteins). Control anionic siRNA conjugated to lipidic moieties displayed no activity at $100 \mathrm{nM}$, and even at doses as high as $500 \mathrm{nM}$ (data not shown), but were able to knockdown gene expression when transfected by Interferin ${ }^{\mathrm{TM}}(10 \mathrm{nM})$.

To test the influence of albumin as a molecular carrier on the efficiency and toxicity of siRNA derivatives, lipophilic cationic siRNA and controls were pre-incubated with excess albumin $(20 \mathrm{mg} / \mathrm{mL})$ for $40 \mathrm{~min}$ before addition onto cells, in serum-free conditions (Fig. 5). In almost all conditions, albumin did not modify significantly the efficiency and toxicity of siRNA. Only Chol $\mathrm{S}_{30} \mathrm{GL} 3$ and $\left(\mathrm{C}_{12}\right)_{2} \mathrm{~S}_{30} \mathrm{GL} 3$ were slightly inhibited by albumin.

Finally, both free and albumin preloaded lipophilic cationic siRNA were tested in the presence of serum (Fig. 6).

Strikingly, except for $\mathrm{CholS}_{30} \mathrm{GL} 3$, albumin-free lipophilic cationic siRNA and cationic siRNA were still capable of ca. $90 \%$ of luciferase expression knockdown for concentrations only twice as high as in the absence of serum: $100 \mathrm{nM}$ for $\mathrm{S}_{30} \mathrm{GL} 3$ and $200 \mathrm{nM}$ for $\left(\mathrm{C}_{12}\right)_{2} \mathrm{~S}_{30} \mathrm{GL} 3$ and $\mathrm{C}_{12} \mathrm{~S}_{30} \mathrm{GL} 3$, respectively. Surprisingly, $\mathrm{CholS}_{30} \mathrm{GL} 3$ reminiscent of the commercially available Accell molecule (Dharmacon) is not able to inhibit significantly luciferase expression at the concentrations that were tested. Here again, high concentration of albumin did not interfere with siRNA delivery.

\section{Discussion}

For gene silencing, only the antisense lead strand [18] is used by the RISC complex to screen mRNAs and cleave its target. Thus, to ensure no off-target effects due to spermine or lipid conjugation, and as intact $5^{\prime}$ antisense position is crucial to maintain RNA interference [19], conjugations were made on the $5^{\prime}$ end of passenger sense strand. Moreover, addition of spermines should increase the stability of the corresponding end of the siRNA duplex and consequently guide the enzymatic complex RISC towards antisense strand selection [20,21]. Nuclease resistance can be obtained by chemically modifying the nucleic acid backbone. However, chemical modifications can also induce reduced efficacy and/or selectivity [22]. For these reasons, siRNA backbone was kept "natural." The oligospermine tail may also protect the siRNA from nuclease degradations, by folding back on the ON backbone, through electrostatic interactions. Another possible way to increase steric hindrance towards nucleases would be to dock cationic siRNA on a protein. As albumin is the major constituent of serum proteins, and has already been used as a carrier for lipophilic drugs and nucleic acids, we synthesized three hydrophobic derivatives of cationic siRNA, containing a $C_{12}$, a $\left(C_{12}\right)_{2}$, or a cholesteryl moiety. Cholesteryl siRNA derivatives are already commercially available, but together with undocumented chemical modifications of the siRNA backbone. Association (docking) of lipophilic siRNA on albumin should ensure a better protection and biodistribution in the case of intravenous delivery [23]. 


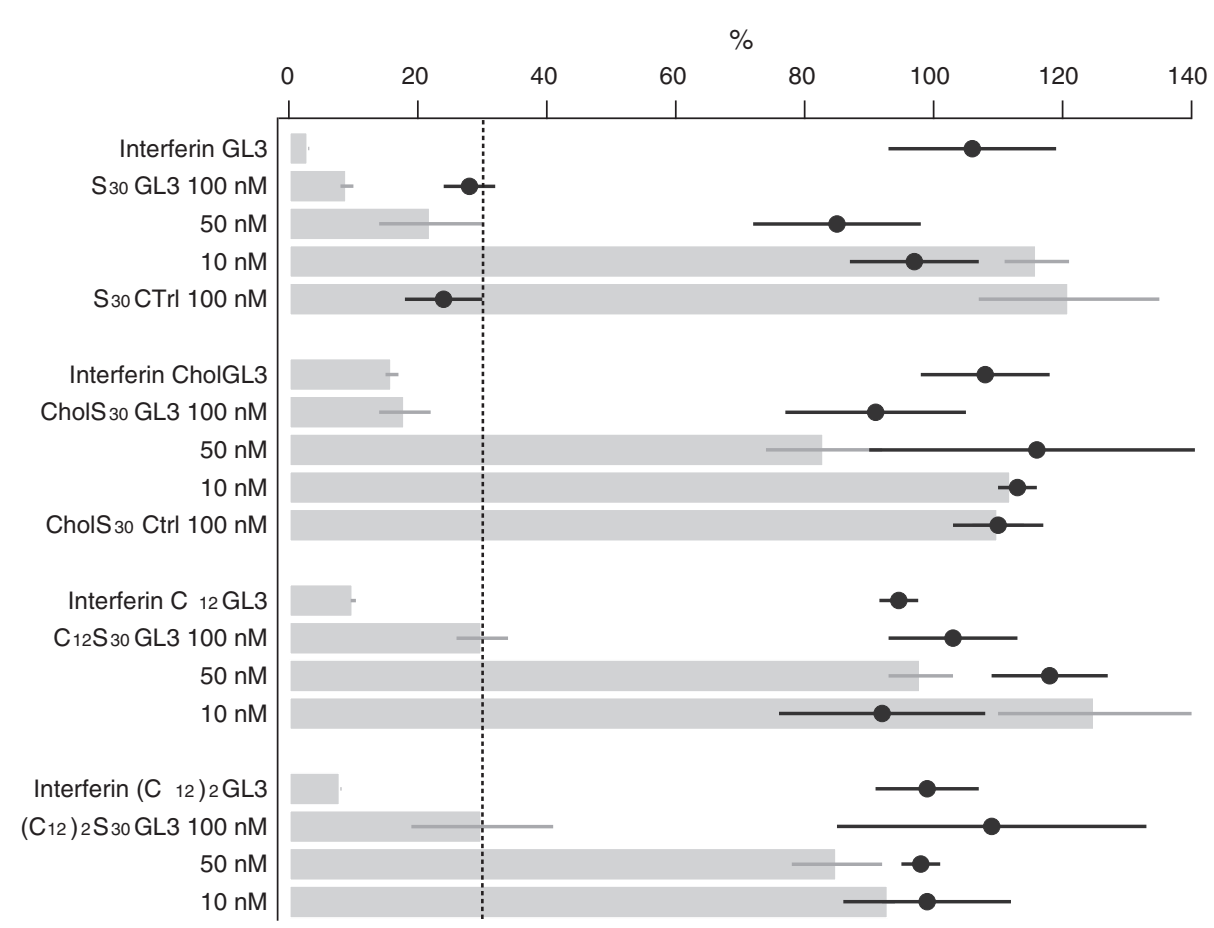

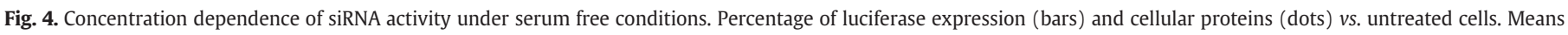
and error bars are given.

The ONs conjugated to both 30 spermines and lipid moieties were prepared by standard phosphoramidite chemistry. However these syntheses suffer from overall low yields, even after optimization of the coupling conditions ( $>95 \%$ average yield). Prolonged coupling time and/or repeated couplings did not further improve the efficiency. Moreover, a considerable part of the material was lost during purification on reverse-phase cartridge. Characterization of these ONs was done by
MALDI-TOF affording usually the expected mass peak within $\pm 100 \mathrm{Da}$ (see SI, less than $0.5 \%$ relative error) using hydroxypicolinic acid or trihydroxyacetophenone combined with diammonium citrate as matrix. It is difficult to observe well-resolved peak when ONs are conjugated to 30 spermines. With $\mathrm{CholS}_{30}$ [GL3], only a weak peak was observed, while the mass peak of $\mathrm{CholS}_{30}[\mathrm{Ctrl}]$ was not detected in these conditions. The $\mathrm{C}_{12}$ - and $\left(\mathrm{C}_{12}\right)_{2}-\mathrm{S}_{30}$-ODNs afforded clearly the mass peaks. The other lipid

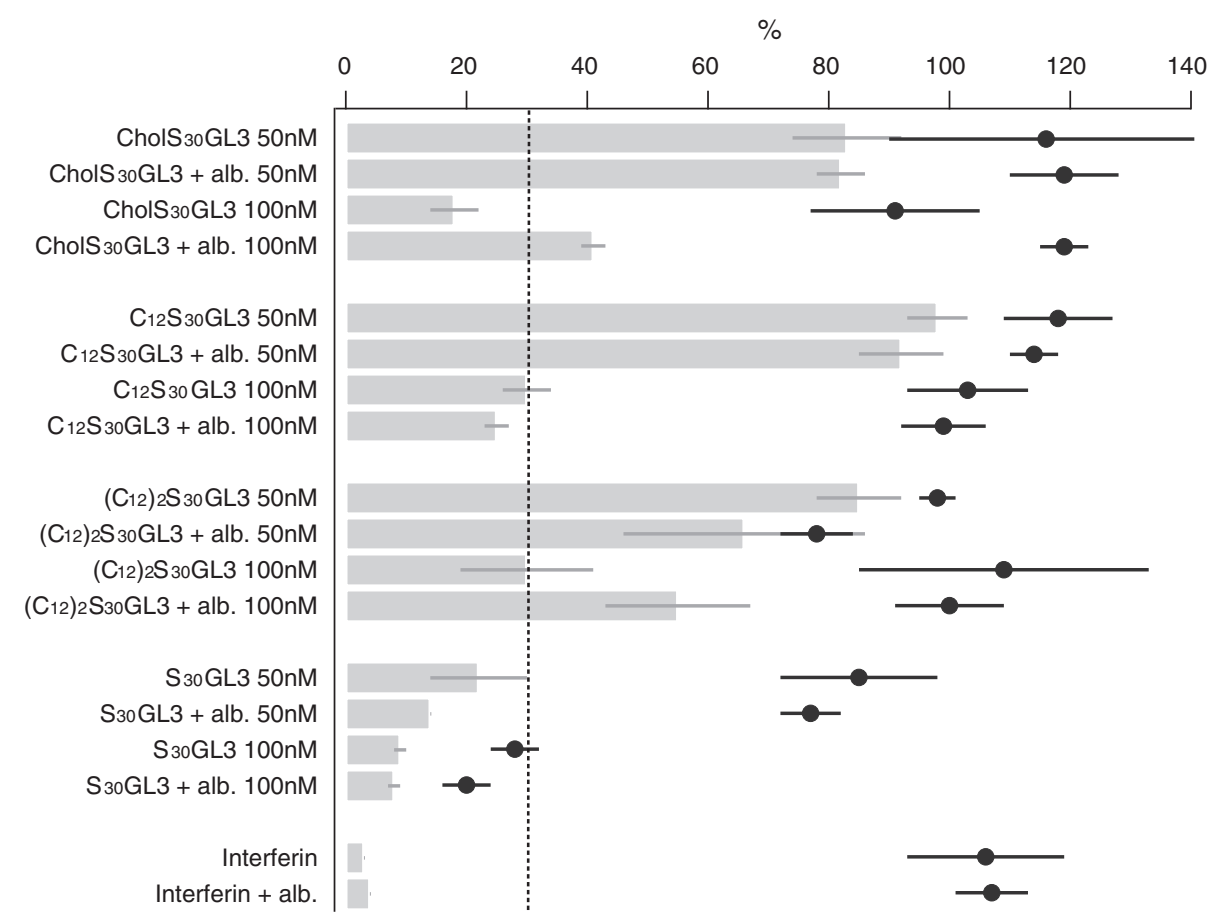

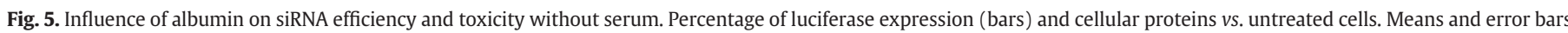
are given. 


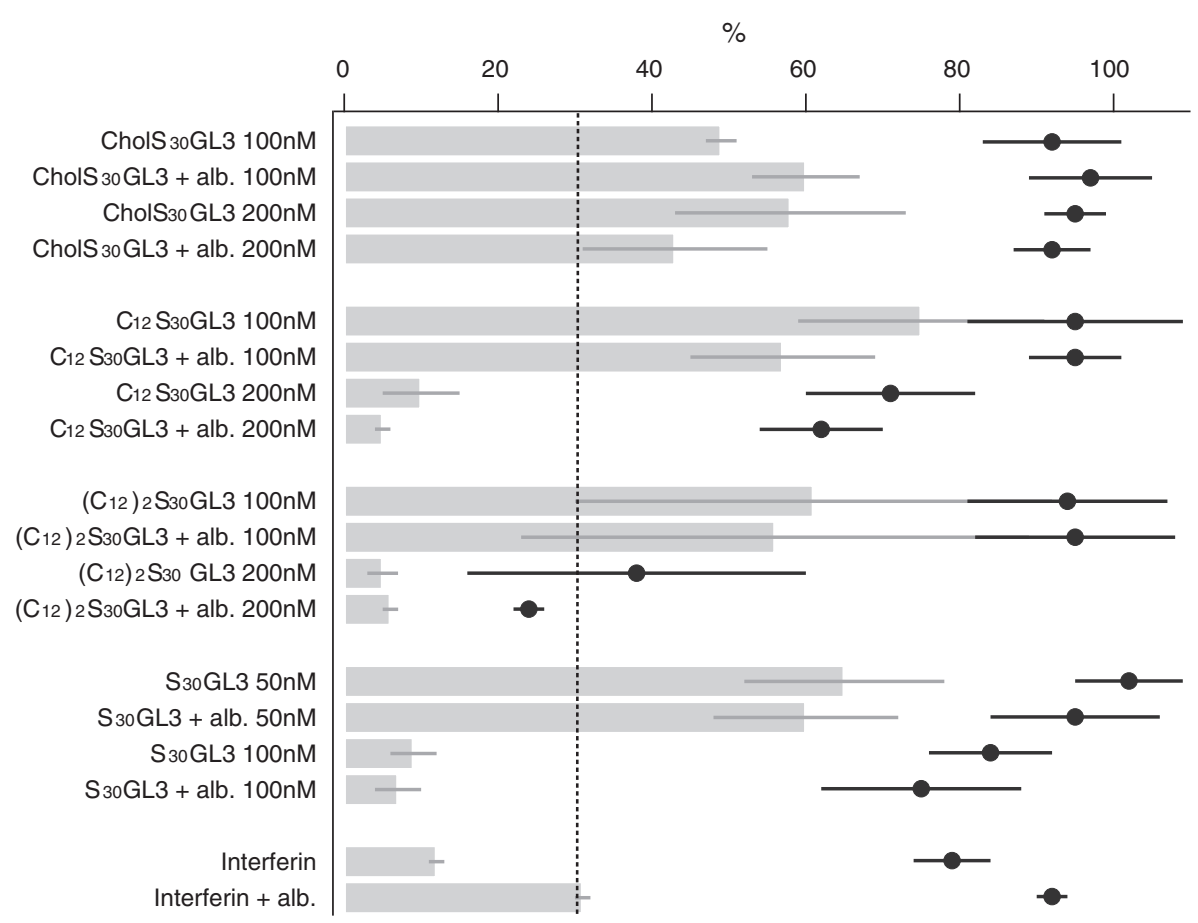

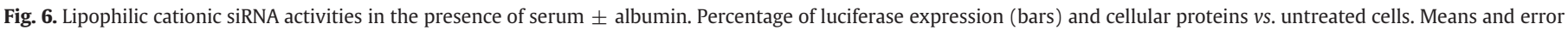
bars are given.

conjugates without spermines gave well-resolved mass peaks of cationic adducts ( $\mathrm{Na}, \mathrm{K})$.

Spermine-coupled ONs did not properly migrate in regular agarose or polyacrylamide gel electrophoresis conditions, most probably due to their zwitterionic nature and overall net cationic charge. However, the experimental setup designed for protein electrophoresis (i.e. MOPSSDS, and Bis-Tris gradient), allowed differential migration of ONs. SDS probably interacts electrostatically with the cationic oligo-spermine tail, leading to charge shielding and even reversal. Therefore, electrophoretic mobility is related to the size/molecular weight and charge of the ON derivatives, inducing differential migration of spermine-modified- vs. natural ONs. Only gradient gels allowed the migration of modified and unmodified ONs on the same gel. PAGE experiment showed contamination of spermine-coupled oligonucleotides by ONs bearing no spermines. The absence of a corresponding molecular peak in MALDI-TOF data (see SI) leads us to hypothesize that electrophoresis conditions are breaking the bond between the first spermine and the last nucleotide by an unknown mechanism, and is not reflecting the actual purity of spermine-ONs and their lipophilic derivatives. However, the smears that appear in various bands may reflect some degradation of ONs. Only CholS ${ }_{30} \mathrm{GL} 3$ single and double stranded ONs clearly exhibited a different migration profile that could be due to the formation of multimeric species, due to the highly hydrophobic cholesteryl moiety.

All cationic ONs were visualized as nanometric structures, ranging from quasi-monomolecular $\left(\mathrm{S}_{30} \mathrm{GL} 3\right)$ to spherical micelles of less than $50 \mathrm{~nm}$, at the exception of the cholesteryl derivative, that was seen as oblong and interlaced micelles. As cationic siRNA and their lipophilic analogues have natural RNA backbones, stability towards serum nucleases and proteins might arise from their ability to form self-assemblies that could protect the genetic material. Alternatively, spermine moiety could fold backwards into the double stranded siRNA. Disappearance of the micelles in the presence of albumin indicates that ionic and Van der Waals interactions with serum protein disrupted the micelles and efficiently loaded lipophilic and/or cationic ONs on proteins. Therefore, albumin can be considered as a carrier for these nucleic acids.

All cationic siRNA successfully inhibited luciferase expression in vitro, at $100 \mathrm{nM}$ in serum-free conditions. One should emphasize that these results were obtained with single molecules (or aggregates of few molecules), as opposed to "large" particles obtained with synthetic vectors, that sediment (therefore concentrate) onto cells during transfection. Cholesteryl cationic siRNA compares favorably with Accell siRNA, as the manufacturer protocols recommends to work at $1 \mu \mathrm{M}$. Negative controls were composed of an irrelevant siRNA sequence coupled to 30 spermines and anionic lipophilic siRNA directed against luciferase (data not shown). None of them was able to silence luciferase expression. At the opposite, vectorization by Interferin ${ }^{\mathrm{TM}}$ of lipophilic siRNA directed against luciferase was able to knock down $>80 \%$ of luciferase expression, showing little (CholGL3) if not no influence of the chemical modifications on biological activity.

As shown by TEM imaging, addition of albumin to cationic siRNA (hydrophilic and lipophilic) led to micelle/aggregate disruption, showing the ionic and/or Van der Waals interactions between them. siRNA was therefore pre-mixed with concentrated albumin prior to transfection. For half of the molecules ( $\mathrm{CholS}_{30} \mathrm{GL} 3$ and $\left(\mathrm{C}_{12}\right)_{2} \mathrm{~S}_{30} \mathrm{GL} 3$ ), efficiency was reduced, whereas for $\mathrm{C}_{12} \mathrm{~S}_{30} \mathrm{GL} 3$ and $\mathrm{S}_{30} \mathrm{GL} 3$, it was slightly increased (at $100 \mathrm{nM}$ ). Reasons for this opposite behavior are unknown.

In the presence of $10 \%$ serum, albumin only interfered with vectorized siRNA, while cationic siRNA was unaffected. The combined effect of serum and albumin probably led to lipid/siRNA particle dismantling. What is more, all but $\mathrm{CholS}_{30} \mathrm{GL} 3$ derivatives remained highly efficient although a two-fold increase in concentrations was necessary $\left(\mathrm{C}_{12} \mathrm{~S}_{30} \mathrm{GL} 3\right.$ and $\left.\left(\mathrm{C}_{12}\right)_{2} \mathrm{~S}_{30} \mathrm{GL} 3\right)$. In particular, $\mathrm{C}_{12} \mathrm{~S}_{30} \mathrm{GL} 3$ combined high efficiency and relatively low toxicity. It is the first report of more than $90 \%$ expression knockdown with non-vectorized siRNA, in $10 \%$ serum-containing medium. This is achieved by both $\mathrm{C}_{12} \mathrm{~S}_{30} \mathrm{GL} 3$ and $\mathrm{S}_{30} \mathrm{GL} 3$, at $200 \mathrm{nM}$ and $100 \mathrm{nM}$, respectively.

\section{Conclusion}

We successfully synthesized three lipophilic cationic siRNA that exhibited similar in vitro activities than their cationic siRNA precursor. We showed that lipidic cationic siRNA and their cationic counterpart were resistant to serum at doses comprised between $100 \mathrm{nM}$ and $200 \mathrm{nM}$, which is promising for further in vivo study. As lipidic 
moieties were added to serve as anchors on serum proteins for in vivo use, we studied the effect of a potential molecular vehicle, albumin, and demonstrated that its presence did neither affect efficiencies nor toxicities of $\mathrm{C}_{12} \mathrm{~S}_{30} \mathrm{GL} 3$ and $\mathrm{S}_{30} \mathrm{GL} 3$ conjugates. Further in vivo study by intravenous injections of these cationic siRNA preloaded on serum albumin to form furtive assemblies and enhance siRNA resistance and diffusion should support the pertinence of our approach [23].

\section{Acknowledgments}

We would like to thank Christine Ruhlman from the imaging center of the Institut de Génétique et de Biologie Moléculaire et Cellulaire, Illkirch, France, for her support in electron microscopy. This work was supported by the French government (MESR), the Universite de Strasbourg (Unistra), and the Association Française contre les Myopathies (AFM). P.P. received a grant from MESR.

\section{Appendix A. Supplementary data}

Supplementary data to this article can be found online at http:// dx.doi.org/10.1016/j.jconrel.2013.04.013.

\section{References}

[1] A. Fire, S. Xu, M.K. Montgomery, S.A. Kostas, S.E. Driver, C.C. Mello, Potent and specific genetic interference by double-stranded RNA in Caenorhabditis elegans, Nature 391 (1998) 806-811.

[2] S.M. Elbashir, J. Harborth, W. Lendeckel, A. Yalcin, K. Weber, T. Tuschl, Duplexes of 21-nucleotide RNAs mediate RNA interference in cultured mammalian cells, Nature 411 (2001) 494-498.

[3] J. Kurreck, RNA interference: from basic research to therapeutic applications, Angew. Chem. Int. Ed. 48 (2009) 1378-1398.

[4] A.D. Judge, V. Sood, J.R. Shaw, D. Fang, K. McClintock, I. MacLachlan, Sequencedependent stimulation of the mammalian innate immune response by synthetic siRNA, Nat. Biotechnol. 23 (2005) 457-462.

[5] Z. Ma, J. Li, F. He, A. Wilson, B. Pitt, S. Li, Cationic lipids enhance siRNA-mediated interferon response in mice, Biochem. Biophys. Res. Commun. 330 (2005) 755-759.

[6] M. Meyer, C. Dohmen, A. Philipp, D. Kiener, G. Maiwald, C. Scheu, M. Ogris, E. Wagner, Synthesis and biological evaluation of a bioresponsive and endosomolytic siRNApolymer conjugate, Mol. Pharm. 6 (2009) 752-762.
[7] S.A. Moschos, S.W. Jones, M.M. Perry, A.E. Williams, J.S. Erjefalt, J.J. Turner, P.J. Barnes, B.S. Sproat, M.J. Gait, M.A. Lindsay, Lung delivery studies using siRNA conjugated to $\mathrm{TAT}(48-60)$ and penetratin reveal peptide induced reduction in gene expression and induction of innate immunity, Bioconjug. Chem. 18 (2007) 1450-1459.

[8] A. Muratovska, M.R. Eccles, Conjugate for efficient delivery of short interfering RNA (siRNA) into mammalian cells, FEBS Lett. 558 (2004) 63-68.

[9] J. Soutschek, A. Akinc, B. Bramlage, K. Charisse, R. Constien, M. Donoghue, S Elbashir, A. Geick, P. Hadwiger, J. Harborth, M. John, V. Kesavan, G. Lavine, R.K Pandey, T. Racie, K.G. Rajeev, I. Rohl, I. Toudjarska, G. Wang, S. Wuschko, D. Bumcrot, V. Koteliansky, S. Limmer, M. Manoharan, H.-P. Vornlocher, Therapeutic silencing of an endogenous gene by systemic administration of modified siRNAs, Nature 432 (2004) 173-178.

[10] C. Wolfrum, S. Shi, K.N. Jayaprakash, M. Jayaraman, G. Wang, R.K. Pandey, K.G. Rajeev, T. Nakayama, K. Charrise, E.M. Ndungo, T. Zimmermann, V. Koteliansky, M. Manoharan, M. Stoffel, Mechanisms and optimization of in vivo delivery of lipophilic siRNAs, Nat. Biotechnol. 25 (2007) 1149-1157.

[11] A. Eguchi, S.F. Dowdy, siRNA delivery using peptide transduction domains, Trends Pharmacol. Sci. 30 (2009) 341-345.

[12] http://www.dharmacon.com/uploadedFiles/Home/Resources/Protocols/accelldelivery-protocol.pdf.

[13] E. Voirin, J.-P. Behr, M. Kotera, Versatile synthesis of oligodeoxyribonucleotideoligospermine conjugates, Nat. Protoc. 2 (2007) 1360-1367.

[14] B. Pons, M. Kotera, G. Zuber, J.-P. Behr, Online synthesis of diblock cationic oligonucleotides for enhanced hybridization to their complementary sequence, ChemBioChem 7 (2006) 1173-1176.

[15] M. Nothisen, M. Kotera, E. Voirin, J.-S. Remy, J.-P. Behr, Cationic siRNAs provide carrier-free gene silencing in animal cells, J. Am. Chem. Soc. 131 (2009) 17730-17731.

[16] http://www.glenresearch.com/GlenReports/GR19-2.pdf, (in).

[17] E. Morin, M. Nothisen, A. Wagner, J.-S. Remy, Cationic polydiacetylene micelles for gene delivery, Bioconjug. Chem. 22 (2011) 1916-1923.

[18] J. Martinez, A. Patkaniowska, H. Urlaub, R. Lührmann, T. Tuschl, Single-stranded antisense siRNAs guide target RNA cleavage in RNAi, Cell 110 (2002) 563-574.

[19] S.M. Elbashir, W. Lendeckel, T. Tuschl, RNA interference is mediated by 21- and 22-nucleotide RNAs, Genes Dev. 15 (2001) 188-200.

[20] A. Khvorova, A. Reynolds, S.D. Jayasena, Functional siRNAs and miRNAs exhibit strand bias, Cell 115 (2003) 209-216.

[21] D.S. Schwarz, G. Hutvagner, T. Du, Z. Xu, N. Aronin, P.D. Zamore, Asymmetry in the assembly of the RNAi enzyme complex, Cell 115 (2003) 199-208.

[22] S. Shukla, C. Sumaria, P. Pradeepkumar, Exploring chemical modifications for siRNA therapeutics: a structural and functional outlook, ChemMedChem 5 (2010) 328-349.

[23] S. Lau, B. Graham, N. Cao, B.J. Boyd, C.W. Pouton, P.J. White, Enhanced extravasation, stability and in vivo cardiac gene silencing via in situ siRNA-albumin conjugation, Mol. Pharm. 9 (2012) 71-80. 